\title{
Generalized anxiety disorder in primary care: mental health services use and treatment adequacy
}

Pasquale Roberge ${ }^{1 *}$, François Normand-Lauzière ${ }^{1}$, Isabelle Raymond ${ }^{1}$, Mireille Luc ${ }^{1}$, Marie-Michèle Tanguay-Bernard ${ }^{1}$, Arnaud Duhoux ${ }^{2}$, Christian Bocti ${ }^{3}$ and Louise Fournier ${ }^{4}$

\begin{abstract}
Purpose: Generalized Anxiety Disorder (GAD) is a common mental disorder in the primary care setting, marked by persistent anxiety and worries. The aims of this study were to: 1) examine mental health services utilisation in a large sample of primary care patients; 2) explore detection of GAD and minimal standards for pharmacological and psychological treatment adequacy based on recommendation from clinical practice guidelines; 3) examine correlates of treatment adequacy, i.e. predisposing, enabling and needs factors according to the Behavioural Model of Health Care Use.
\end{abstract}

Methods: A sample of 373 adults meeting DSM-IV criteria for Generalized Anxiety Disorder in the past 12 months took part in this study. Data were drawn from the "Dialogue" project, a large primary care study conducted in 67 primary care clinics in Quebec, Canada. Following a mental health screening in medical clinics $(n=14833)$, patients at risk of anxiety or depression completed the Composite International Diagnostic Interview-Simplified (CIDIS). Multilevel logistic regression models were developed to examine correlates of treatment adequacy for pharmacological and psychological treatments.

Results: Results indicate that $52.5 \%$ of participants were recognized as having GAD by a healthcare professional in the past 12 months, and $36.2 \%$ of the sample received a pharmacological (24.4\%) and/or psychological treatment $(19.2 \%)$ meeting indicators based on clinical practice guidelines recommendations. The detection of GAD by a health professional and the presence of comorbid depression were associated with overall treatment adequacy.

Conclusions: This study suggests that further efforts towards GAD detection could lead to an increase in the delivery of evidence-based treatments. Key targets for improvement in treatment adequacy include regular follow up of patients with a GAD medication and access to psychotherapy from the primary care setting.

Keywords: Generalized Anxiety Disorder, Quality indicators, Treatment Adequacy, Primary Care, Service Utilization, Psychotherapy, Pharmacotherapy

\section{Background}

Generalized Anxiety Disorder (GAD) is a common mental disorder marked by persistent anxiety and worries, which are excessive and difficult to control, as well as multiple psychological and physical symptoms [1]. GAD often has a chronic course [2-6] with a lifetime prevalence rate for

\footnotetext{
* Correspondence: pasquale.roberge@usherbrooke.ca

'Department of Family Medicine and Emergency Medicine, Faculty of Medicine and Health Sciences, Université de Sherbrooke, 3001,12th Avenue North, Sherbrooke, QC J1H 5 N4, Canada

Full list of author information is available at the end of the article
}

DSM-IV criteria estimated at approximately $6 \%$ [7-10]. Persons suffering from GAD present significant impairments in work, social and family functioning, and healthrelated quality of life [11-16]. There is also increasing evidence regarding the economic burden of GAD in terms of lost work productivity and medical costs due to high utilization of medical services $[8,15,17,18]$. GAD is highly associated with comorbid psychiatric disorders, with major depressive disorder being the most frequent $[2,3,11,19-21]$, and comorbid physical illness [22]. 
Previous research has exposed the challenges to the detection and treatment of mental disorders in primary care [23]. Research has typically shown low rates of recognition of GAD by primary care providers [8-10, 24-28]. For GAD in particular, it has been suggested that underrecognition may be due to vague somatic symptoms, to patient's attribution of symptoms to physical problems, to an ill-defined diagnosis [2] and to the variety of clinical presentations [5], which may depend on the symptom overlap with comorbid psychiatric disorders and somatic diseases [2, 29-32].

Patients with GAD often consult in the primary care setting [8] and it is generally agreed that most cases should be treated in primary care [2]. Clinical practice guidelines recommend either pharmacological treatments (e.g. SSRIs and venlafaxine) or cognitive behaviour therapy as first choice treatments for GAD, and long-term therapy may be needed to prevent relapse [33-35]. Previous studies have reported treatment adequacy rates for patients with GAD ranging from $24.6 \%$ to $42.5 \%$ in epidemiological surveys in Canada, United States, Spain and Australia [17, 36-38], 44.2 \%-43.8 \% [39, 40] in clinical studies in the United States and $49.5 \%$ in a primary care sample in the Netherlands [41]. While GAD shares common characteristics with other anxiety disorder, we cannot assume that the determinants of potentially adequate psychological and pharmacological treatments are similar across anxiety disorders. For instance, research has shown that perceived need for treatment, help-seeking behaviour, service utilization, as well as recognition and treatment of common mental disorders by health care professionals vary across common mental disorders, which may impact on the probability of receiving potentially adequate treatments [38].

Despite the burden of GAD, data on patterns of service utilization, detection rates and treatment gap are lacking for this common anxiety disorder in the primary care setting. While common mental disorders treatment adequacy data is useful for policy planning, further data on disorder-specific treatment adequacy in primary care is also needed to inform quality improvement initiatives and reduce the gap between guidelines' recommendations and clinical practice for GAD. We sought to examine mental health services utilisation in a large sample of primary care patients of Québec, Canada. A second aim of our investigation was to explore detection of GAD and minimal standards of pharmacological and psychological treatment adequacy for GAD based on recommendation from clinical practice guidelines. To our knowledge, only one study has provided estimates of treatment adequacy for GAD with a large naturalistic primary care sample in Europe [41]. The primary care perspective, in contrast with epidemiological survey or clinical trials, is important because these patients are in contact with the health care system and anxiety disorders are generally treated in the primary care setting [38, 42, 43]. As in previous studies, we expected low rates of recognition and evidence-based treatment of GAD. Finally, we also sought to examine individual-level correlates of treatment adequacy using Andersen's Behavioural Model of Health Care [44] to examine the contribution of conceptually distinct predisposing factors, enabling factors and need for care factors associated with treatment adequacy for GAD. The widely used framework considers individual and contextual characteristics associated with service use. We expected that both GAD recognition and the presence of comorbid depression would improve the likelihood of treatment adequacy for primary care patients. Major depression is associated with increased severity and functional impairment of GAD [45].

\section{Methods}

\section{Study setting, participants and data collection}

Data were drawn from the "Dialogue" project, which included a large cohort study to examine mental health status, service utilization and experience of care of primary care patients with anxiety or depressive disorders [46]. Data for the current study were drawn from the waiting room screening questionnaire (T0) and the first telephone/web interview (T1). The study received the approval of all regional research ethics committees (Agence de santé de des services sociaux de Montréal; Centres de santé de des services sociaux de Chicoutimi, Sherbrooke, Gatineau, Laval, Saint Jérome, Jeanne-Mance, Lac-Saint-Jean-Est, Pointe-De-L'ile, Bordeaux-CartiervilleSaint-Laurent, Therese-De-Blainville, Pierre Boucher, Haut-Richelieu-Rouville, Baie des Chaleurs, La Pommeraie; Hospital Notre-Dame and Hospital Sacré-Coeur). Study participants provided written informed consent.

\section{Waiting room interview (T0)}

Participants were recruited in 2008 in the waiting rooms of 67 primary care medical clinics (T0) during randomly chosen periods. Patients were invited by a lay-interviewer to complete a brief self-administered screening questionnaire if they met the following inclusion criteria: 1) age 18 years or older; 2) consulting a general practitioner for themselves; 3 ) able to complete a questionnaire in French or English. From the 22600 eligible patients approached, $67.4 \%(\mathrm{n}=14833)$ completed the questionnaire. The screening questionnaire included general questions about socio-demographic characteristics, overall health status, consultations with health care providers, psychotropic medication, as well as the Hospital Anxiety and Depression scale (HADS) [47, 48].

\section{Telephone/web structured interview (T1)}

Patients were invited to participate in the first part of T1 $(\mathrm{n}=7$ 522) structured interview if their usual care source 
was one of the participating clinics and if they met at least one of the following inclusion criteria: i) elevated anxiety and/or depressive symptoms; ii) anxiety and/or depression medication in the past 12 months; iii) depressive and/or anxiety disorders diagnosis made by a physician; iv) consultation for mental health problems in the past 12 months. Among them, 4506 (59.9 \%) accepted to participate to the follow-up and provided their contact details. After 2-4 weeks, we were able to contact by telephone and/or email 3382 (75.1\%) individuals and they completed either the telephone $(70.8 \%)$ or web (29.2 \%) questionnaires. The first part of the questionnaire comprised a brief, structured psychiatric interview for lay interviewers that indicated the extent to which symptoms met the DSM-IV diagnostic criteria for common mental disorders, i.e. the Composite International Diagnostic Interview-Simplified (CIDIS) [49].

The interview then continued (second part of T1) with the 1956 people meeting any of the following criteria: i) meeting DSM-IV criteria for generalized anxiety disorder, panic disorder, agoraphobia, social phobia or depression in the last 12 months; ii) a high level of anxiety or depression symptoms combined with medication use, diagnosis by a health care professional, or DSM-IV criteria for anxiety or depression in the past 24 months. This second part of the interview included questions on experience of care, services utilization for emotional reasons, medication use for anxiety or depressive symptoms, perceived needs for care and socio-demographic data. For the present study, the final sample included 373 adults meeting the criteria for GAD during the 12 months preceding the survey Fig. 1 .

\section{Indicators for the detection of GAD, service utilization and treatment adequacy}

Indicators for the detection of GAD in our sample were defined as: 1) reporting a diagnosis of GAD by a physician over the lifetime; 2) being informed in the past 12 months by a healthcare professional that they were suffering from GAD. Indicators for service utilization comprised: 1) being hospitalized for at least one night for mental health reasons in the past 12 months; 2) consulting at least one health professional for mental health reasons in the past 12 months, including a general practitioner, a psychologist, a social worker, counsellor or psychotherapist, a psychiatrist, a nurse or a medical specialist (other than a psychiatrist). Quality indicators for pharmacological and psychological management of GAD were established from the Clinical practice guidelines: Management of anxiety disorders published in 2006 by the Canadian Psychiatric Association [34]. We also built on previous research on treatment adequacy for anxiety and depression to expand our treatment adequacy indicators and explore other aspects of care that were not explicitly advocated in the guidelines [39, 40, 46, 50-52]. Two principal definitions of potentially adequate treatment were developed for the management of GAD. First, potentially adequate pharmacological treatments were defined as: receiving a first-line, second-line or third-line agent for GAD at an adequate dosage, plus at least 3 consultations with a general practitioner or psychiatrist. Benzodiazepines were not included as adequate medication because they are only recommended as a short-term adjunct medication for most patients. Second, the criteria for adequate psychotherapy were defined as: at least 12 psychotherapy sessions with the same mental health professional and a cognitive behavioural treatment. Overall adequacy was then defined as meeting criteria for either one or both psychological or pharmacological treatment adequacy. The comprehensive list of quality indicators regarding service use, GAD detection and treatment is presented in Table 2.

\section{Individual-level patient characteristics}

Patient characteristics were conceptually grouped into predisposing, enabling, and needs factors according to Andersen's Behavioural Model of Health Services Use [44]. Predisposing factors included sex, age (18-24; 25$44 ; 45-59 ; 60+$ ), educational attainment (high school or less; college degree; university degree) and marital status (married/living together; separated/divorced/widowed; single). Enabling factors included perception of economic situation (financially secure; sufficient; poor/very poor), having a family physician and having private or collective insurance coverage for medication or complementary health services. Need for care factors included suffering from a depressive disorder or other co-morbid anxiety disorders in the past 12 months and the number of chronic physical illnesses (0, 1, 2, 3 or more).

\section{Statistical analysis}

Descriptive analyses were conducted to examine sociodemographic and clinical characteristics of the sample, as well as overall service use and quality indicators for primary care patients with GAD. Analyses were carried out for the following adequacy indicators: 1) pharmacological treatment, 2) psychological treatment, 3) pharmacological and/or psychological treatment. We first calculated bivariate associations between aforementioned variables and treatment adequacy using logistic regressions. Given the hierarchical structure i.e. patients within primary care clinics, 2-level multilevel analyses were conducted using glmer. The empty model was first assessed with only clinical ID's to identify the degree of association among observations within the clusters. In a second step, multilevel models were assessed for each adequacy with clinical ID's as a random intercept [53]. Variables integrated in the models were based on the level of significance in the bivariate models $(\mathrm{p}<=.10)$. Although not reaching this criterion, sex was included as a control variable. Statistical 


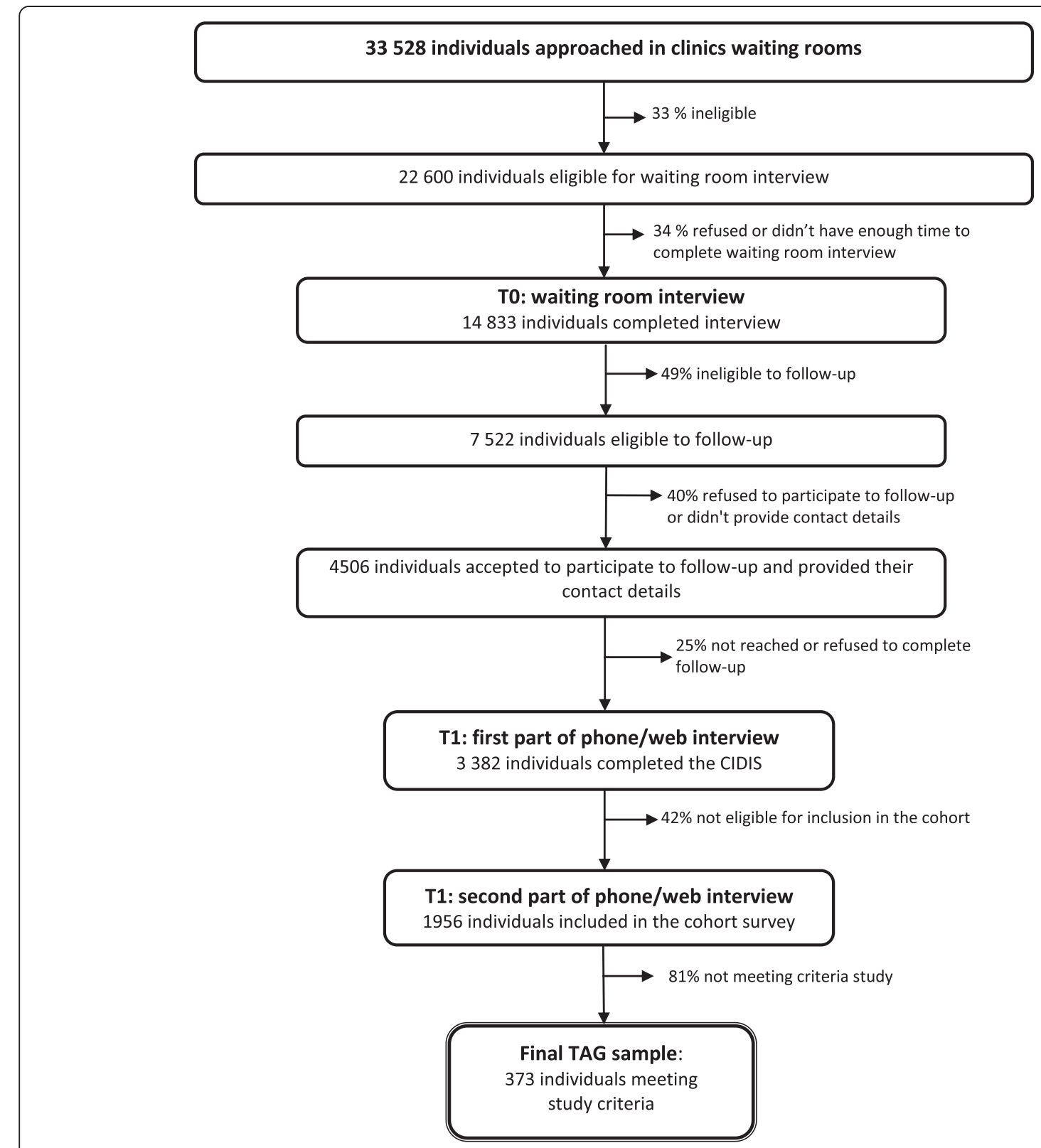

Fig. 1 Recruitment flow-chart, Dialogue Project, 2008

analyses were performed using SPSS 20 statistical software and R 3.1.1.

\section{Results}

\section{Patient characteristics}

Table 1 summarizes the individual characteristics of the 373 participants meeting DSM-IV criteria for GAD in the 12 months preceding their interview. Participants with GAD were predominantly female $(76.7 \%)$. The mean age of participants was 42.2 years old $(\mathrm{SD}=13.2)$ and more than $80 \%$ were aged between 25 and 59 years. Slightly more than half were married or living with a partner $(53.1 \%)$ and more than half had completed a college or university degree. The sample was predominantly urban, approximately half was working or studying full-time (47 \%) and over two thirds perceived their income as sufficient or felt financially secure.

The majority reported having a family physician, nearly two thirds had private medication coverage and over one half had access to supplementary insurance coverage for complementary health services. The mean age of onset of GAD was in the late twenties (28.9 years, $\mathrm{SD}=13.2)$, and nearly two thirds had had GAD for over 5 years. The presence of psychiatric comorbidity was frequent: in the past 12 months, $71 \%$ of participants also met the criteria for major depression and $60.6 \%$ had a comorbid anxiety 
Table 1 Individual Characteristics of Participants $(n=373)$

\begin{tabular}{|c|c|c|}
\hline CHARACTERISTICS & $\mathrm{N}$ & $\%$ \\
\hline Sex (female) & 286 & 76.7 \\
\hline \multicolumn{3}{|l|}{ Age group, years } \\
\hline $18-24$ & 37 & 9.9 \\
\hline $25-44$ & 167 & 44.9 \\
\hline $45-59$ & 139 & 37.4 \\
\hline 60 and over & 29 & 7.8 \\
\hline \multicolumn{3}{|l|}{ Marital status } \\
\hline Married/Living together & 198 & 53.1 \\
\hline Separated/Divorced/Widowed & 64 & 17.2 \\
\hline Single & 111 & 29.8 \\
\hline \multicolumn{3}{|l|}{ Education level } \\
\hline High school degree or less & 173 & 46.4 \\
\hline Collegial degree & 105 & 28.2 \\
\hline University degree & 95 & 25.5 \\
\hline \multicolumn{3}{|l|}{ Patient perception of his income } \\
\hline Financially secure & 49 & 13.2 \\
\hline Sufficient & 203 & 54.6 \\
\hline PoorNery poor & 120 & 32.3 \\
\hline Private medication insurance coverage (Yes) & 245 & 65.9 \\
\hline $\begin{array}{l}\text { Supplementary insurance coverage for complementary } \\
\text { health services (Yes) }\end{array}$ & 202 & 55.0 \\
\hline Has a family physician (Yes) & 308 & 83.5 \\
\hline $\begin{array}{l}\text { Comorbid anxiety disorder (social anxiety disorder, panic } \\
\text { disorder, agoraphobia) }\end{array}$ & 226 & 60.6 \\
\hline Social anxiety disorder & 124 & 33.2 \\
\hline Agoraphobia & 129 & 34.6 \\
\hline Panic disorder & 131 & 35.1 \\
\hline Comorbid major depression & 265 & 71.0 \\
\hline \multicolumn{3}{|l|}{ Comorbid chronic illnesses } \\
\hline 0 & 65 & 17.4 \\
\hline 1 & 89 & 23.9 \\
\hline 2 & 80 & 21.4 \\
\hline 3 or more & 139 & 37.3 \\
\hline
\end{tabular}

disorder. The majority of participants (82.6\%) experienced at least one chronic physical condition.

\section{Indicators of care}

Table 2 presents descriptive data on our indicators of service utilization, detection of GAD as well as pharmacological and psychological treatments. The prevalence of service use for mental health problems in the past 12 months was high $(89.5 \%)$. The health professionals most frequently consulted were general practitioners (87.4 \%), psychologists (53.8 \%) and psychiatrists (28.5 \%). The majority of participants $(54.4 \%)$ received a referral by a primary care physician to consult a mental health specialist, either a psychologist (40.8\%) or a psychiatrist (22.8\%). Over 1 in 10 participants were hospitalized at least one night for mental health reasons in the past 12 months.

Based on our indicators for the detection of GAD, $67.2 \%$ of participants reported being informed by a physician that they were suffering from an anxiety disorder during their life course and $52.5 \%$ specifically of GAD in the past 12 months by a healthcare professional.

Overall, $36.2 \%$ of the sample received a pharmacological and/or psychological treatment qualified as adequate according to our indicators of care. For pharmacological treatments, nearly two thirds of the participants had received a psychotropic medication and SSRIs were the most frequently prescribed class of medication $(31.4 \%)$. The indicator of pharmacological treatment adequacy was met for $24.4 \%$ of the sample based on medication, dosage, duration and follow up (see Table 2). For psychotherapy, over one half of participants reported obtaining some form of psychotherapy or counselling, and slightly less than one half obtained at least 15 minutes or more of psychotherapy or counselling. The most frequently reported psychotherapeutic approaches were problem-solving therapy and cognitive behavioural therapy (CBT). The indicator of psychological treatment adequacy was met for $19.2 \%$ of the sample based on the number of sessions of psychotherapy by a same healthcare professional and exposure to a CBT approach.

\section{Factors associated with treatment adequacy}

Table 3 presents the results of the multilevel logistic regression analyses showing predisposing, enabling and needs factors associated with adequate pharmacological and psychological treatments for the sample.

\section{Pharmacological treatment adequacy}

A total of 357 cases were analyzed for the pharmacological treatment adequacy status. Proportion of variance explained by the random effect (intra-class correlation (ICC)) of clinical IDs was $11 \%$. One predisposing factor, marital status, was associated the reception of adequate pharmacological treatment. Compared to single participants, those who were separated, divorced or widowed were three times more likely to obtain adequate pharmacological treatment $(\mathrm{OR}=2.99 ; 95 \%$ CI [1.40-6.39]). Participants who had a family physician were three times more likely to receive adequate pharmacotherapy ( $\mathrm{OR}=3.11 ; 95 \% \mathrm{CI}$ [1.30-7.43]), and detection of GAD by a health professional also increased the odds of treatment adequacy $(\mathrm{OR}=3.89 ; 95 \%$ CI [2.18-6.94]).

\section{Psychological treatment adequacy}

A total of 345 cases were analyzed for the psychotherapy treatment adequacy status. Table 3 presents the odd ratios 
Table 2 Service Use and Indicators of Services Received in the Past Twelve Months

\begin{tabular}{|c|c|c|}
\hline INDICATORS & $\mathrm{N}$ & $\%$ \\
\hline \multicolumn{3}{|l|}{ Service use } \\
\hline Was hospitalized for at least one night for mental health reasons & 42 & 11.3 \\
\hline Consulted at least one health professional for mental health reasons & 334 & 89.5 \\
\hline General practitioner & 292 & 87.4 \\
\hline Psychologist & 179 & 53.8 \\
\hline Social worker/counsellor/ psychotherapist & 118 & 35.4 \\
\hline Psychiatrist & 95 & 28.5 \\
\hline Nurse & 80 & 24.1 \\
\hline Other medical specialist & 40 & 12.1 \\
\hline Detection by a physician of an anxiety disorder during life course & 240 & 67.2 \\
\hline Detection by a healthcare professional of GAD in the past 12 months & 191 & 52.5 \\
\hline \multicolumn{3}{|l|}{ Pharmacotherapy } \\
\hline Received any psychotropic medication & 239 & 64.1 \\
\hline SSRIs & 117 & 31.4 \\
\hline Other & 103 & 27.6 \\
\hline Benzodiazepines & 92 & 24.7 \\
\hline Antipsychotics & 44 & 11.8 \\
\hline MAOls & 22 & 5.9 \\
\hline Anticonvulsants & 3 & 0.8 \\
\hline TCA & 0 & 0 \\
\hline Received an evidence-based GAD medication & 203 & 54.4 \\
\hline Received an evidence-based GAD medication at an adequate dosage & 182 & 48.8 \\
\hline $\begin{array}{l}\text { Received an evidence-based GAD medication at an adequate dosage, } \\
\text { plus at least } 3 \text { consultations with a general practitioner or psychiatrist }\end{array}$ & 99 & 26.5 \\
\hline $\begin{array}{l}\text { Received an evidence-based GAD medication at an adequate dosage for at least } \\
\text { six months plus at least } 3 \text { consultations with a general practitioner or psychiatrist }{ }^{a}\end{array}$ & 91 & 24.4 \\
\hline \multicolumn{3}{|l|}{ Psychotherapy } \\
\hline Any form of psychotherapy or counselling & 202 & 54,3 \\
\hline Any form of psychotherapy or counselling lasting $\geq 15$ minutes & 175 & 48.1 \\
\hline Problem solving therapy & 143 & 84.1 \\
\hline CBT & 137 & 80.1 \\
\hline Interpersonal psychotherapy & 97 & 58.8 \\
\hline Psychotherapy with $\geq 12$ sessions with a same healthcare professional & 84 & 23.1 \\
\hline Psychotherapy, CBT approach and $\geq 12$ sessions with a same healthcare professional ${ }^{b}$ & 70 & 19.2 \\
\hline \multicolumn{3}{|l|}{ Pharmacotherapy and/or Psychotherapy } \\
\hline Received an evidence-based pharmacological treatment and/or psychotherapy & 135 & 36.2 \\
\hline
\end{tabular}

aur indicator for potentially adequate pharmacotherapy

${ }^{\mathrm{b}}$ Our indicator for potentially adequate psychotherapy

and confidence intervals for the model's significant predictors. Proportion of variance explained by the random effect (ICC) of clinical IDs was around $0 \%$. The predisposing factors associated with adequate psychological treatment included only age group. Belonging to the 45-59 age group, compared to 25-44 age group, was associated with decreased odds of receiving adequate psychological treatment
$(\mathrm{OR}=0.48 ; 95 \% \mathrm{CI}[0.25-0.92])$. The only enabling factor associated with psychological treatment adequacy was the detection of GAD by a health professional (OR $=2.94 ; 95 \%$ CI [1.56-5.52]). For needs factors, the presence of a comorbid anxiety disorder $(\mathrm{OR}=0.51$; $95 \% \mathrm{CI}$ [0.28-0.94]) reduced the odds of reception of an adequate psychological treatment. 
Table 3 Predisposing, Enabling and Needs Factors Associated with Treatment Adequacy

\begin{tabular}{|c|c|c|c|c|c|c|c|c|c|}
\hline & \multicolumn{3}{|c|}{$\begin{array}{l}\text { Pharmacotherapy }{ }^{a} \\
(N=357)\end{array}$} & \multicolumn{3}{|c|}{$\begin{array}{l}\text { Psychotherapy }{ }^{b} \\
(N=345)\end{array}$} & \multicolumn{3}{|l|}{$\begin{array}{l}\text { Overall }^{\mathrm{C}} \\
(N=307)\end{array}$} \\
\hline & \multirow[b]{2}{*}{$\begin{array}{l}\text { Bivariate } \\
\text { Associations }\end{array}$} & \multicolumn{2}{|c|}{$\begin{array}{l}\text { Multivariate Associations } \\
\text { (Final Model) }\end{array}$} & \multirow[b]{2}{*}{$\begin{array}{l}\text { Bivariate } \\
\text { Associations }\end{array}$} & \multicolumn{2}{|c|}{$\begin{array}{l}\text { Multivariate Associations } \\
\text { (Final Model) }\end{array}$} & \multirow[b]{2}{*}{$\begin{array}{l}\text { Bivariate } \\
\text { Associations }\end{array}$} & \multicolumn{2}{|c|}{$\begin{array}{l}\text { Multivariate Association } \\
\text { (Final Model) }\end{array}$} \\
\hline & & OR (95 \% Cl) & $P$ & & OR $(95 \% \mathrm{Cl})$ & $P$ & & OR $(95 \% \mathrm{Cl})$ & $P$ \\
\hline & P & & & $P$ & & & P & & \\
\hline \multicolumn{10}{|l|}{ Predisposing factors } \\
\hline Gender (female) & .613 & $0.95(0.52-1.76)$ & .873 & .086 & $2.16(1.00-4.68)$ & .052 & .526 & $1.32(0.77-2.31)$ & 0.311 \\
\hline \multicolumn{10}{|l|}{ Age group } \\
\hline $25-44$ (ref) & & & & & 1.00 & & & & \\
\hline $18-24$ & .384 & & & .475 & $0.90(0.32-2.50)$ & .836 & .581 & & \\
\hline $45-59$ & .181 & & & .008 & $0.48(0.25-0.92)$ & .026 & .938 & & \\
\hline $60+$ & .806 & & & .083 & $0.45(0.12-1.72)$ & .246 & .598 & & \\
\hline \multicolumn{10}{|l|}{ Education } \\
\hline $\begin{array}{l}\text { High school degree or } \\
\text { less (ref) }\end{array}$ & & 1.00 & & & 1.00 & & & & \\
\hline Collegial degree & .790 & $0.86(0.46-1.60)$ & .638 & .705 & $0.75(0.35-1.60)$ & .455 & .723 & & \\
\hline University degree & .091 & $0.56(0.28-1.31)$ & .107 & .003 & $1.96(0.98-3.94)$ & .057 & .337 & & \\
\hline \multicolumn{10}{|l|}{ Marital status } \\
\hline Single (ref) & & 1.00 & & & & & & & \\
\hline Married/Living together & .853 & $0.91(0.48-1.72)$ & .775 & .163 & & & .568 & & \\
\hline $\begin{array}{l}\text { Separated/Divorced/ } \\
\text { Widowed }\end{array}$ & .001 & $2.99(1.40-6.39)$ & .005 & .114 & & & .160 & & \\
\hline \multicolumn{10}{|l|}{ Enabling factors } \\
\hline \multicolumn{10}{|l|}{$\begin{array}{l}\text { Patient perception } \\
\text { of income }\end{array}$} \\
\hline PoorNery poor (ref) & & & & & 1.00 & & & & \\
\hline Sufficient & .810 & & & .437 & $1.18(0.57-2.48)$ & .651 & .192 & & \\
\hline Financially secure & .456 & & & .018 & $2.03(0.80-5.14)$ & .134 & .813 & & \\
\hline $\begin{array}{l}\text { Private medication insurance } \\
\text { coverage (Yes) }\end{array}$ & .302 & & & .252 & & & .483 & & \\
\hline $\begin{array}{l}\text { Private insurance coverage } \\
\text { for complementary health } \\
\text { services (Yes) }\end{array}$ & .612 & & & .068 & $1.16(0.61-2.21)$ & .658 & .712 & & \\
\hline Has a family physician (Yes) & .026 & $3.11(1.30-7.43)$ & .011 & .591 & & & .069 & $1.90(1.01-3.71)$ & 0.051 \\
\hline $\begin{array}{l}\text { GAD detected by health } \\
\text { professional in the past } \\
12 \text { months (Yes) }\end{array}$ & $<.001$ & $3.89(2.18-6.94)$ & $<.001$ & .006 & $2.94(1.56-5.52)$ & .001 & $<.001$ & $3.14(1.98-5.04)$ & $<0.001$ \\
\hline \multicolumn{10}{|l|}{ Needs factors } \\
\hline Comorbid major depression & .028 & $1.68(0.90-3.16)$ & .106 & .201 & & & .009 & $1.82(1.09-3.08)$ & 0.024 \\
\hline Comorbid anxiety disorder & .973 & & & .022 & $0.51(0.28-0.94)$ & .031 & .135 & & \\
\hline \multicolumn{10}{|l|}{ Comorbid chronic illnesses } \\
\hline 0 & .154 & & & .805 & & & .161 & & \\
\hline 1 & .121 & & & .683 & & & .104 & & \\
\hline 2 & .359 & & & .602 & & & .743 & & \\
\hline
\end{tabular}


Table 3 Predisposing, Enabling and Needs Factors Associated with Treatment Adequacy (Continued)

3 or more (ref)
Random factor (Variance components)
Clinic ID (Intercept)
NOTES: Bivariate association's threshold is $p \leq 0.10$. If no ORs are written for a model, associate variables are not included in the corresponding model
Gender is included in all final models (all non-significant)
andicator defined as: adequate GAD medication at an adequate dosage, plus at least 3 consultations with a general practitioner or psychiatrist
b Indicator defined as: psychotherapy with a CBT approach and $\geq 12$ sessions of at least 15 minutes with the same healthcare professional
Indicator defined as: adequate pharmacological $^{a}$ and/or adequate psychological ${ }^{b}$ treatment

\section{Overall adequacy}

Three hundred seven cases were analyzed for the overall adequacy, meaning that an individual met criteria for either one or both psychological or pharmacological treatment adequacy. The ICC of clinical IDs was near $0 \%$. The detection of GAD by a health professional $(\mathrm{OR}=3.14 ; 95 \% \mathrm{CI}$ [1.98-5.04]), an enabling factor, and the presence of comorbid depression ( $\mathrm{OR}=1.82$; $95 \%$ CI [1.09-3.08]), a needs factor, were associated with overall treatment adequacy.

We did not observe significant differences between clinics in the treatment adequacy models. With 373 individuals separated within 65 primary care medical clinics, the ICC can be as low as zero (only one individual sampled in a clinic) and with a mean of six patients/clinic there is not enough variance within each clinic for the multilevel models to be noticeably different. Furthermore, a likelihood ratio test statistic based on full and reduced models (data not shown) was used to compare the models with and without the random effect and the null hypothesis was not rejected. HADS scores and diagnosis were also integrated in the regression models (data not shown) but did not add any relevant effect.

\section{Discussion}

Results of our study indicate that $89.5 \%$ of GAD sufferers in our primary care sample had consulted at least one health care provider for mental health reasons in the past 12 months, typically a general practitioner or a psychologist. As the recruitment of primary care patients necessarily indicates that they are in contact with at least one clinician, but not necessarily for mental health reasons, the data provides an original perspective on quality of care for patients that are actually exposed to clinical practice, which offers the opportunity for clinicians to actually provide mental health care to their patients. The majority of patients had been recognized as having an anxiety disorder in their lifetime $(67.2 \%)$ and more specifically a GAD (52.5\%) by a health care professional in the past 12 months. While these recognition rates are higher than expected, they may be explained in our sample by high rates of mental health service use, long-term GAD symptoms and profiles of psychiatric comorbidity, particularly with major depression. This is consistent with previous research that showed that comorbid psychiatric disorders and symptom severity facilitate detection of anxiety disorders, while excessive worry may not be sufficient for health care professionals to recognize GAD as well as for patients to decide to seek mental health care [14, 26, 54-56].

In our sample, $36.2 \%$ of patients with GAD reported patterns of service use that met overall minimal standards of treatment adequacy based on clinical practice guidelines recommendations in the past 12 months. While our results are within range of prior studies, more stringent criteria for treatment adequacy in our study could explain variations. As seen in previous studies for anxiety disorders [42], treatment adequacy rates were higher for pharmacotherapy $(24.4 \%)$ than for psychotherapy (12.9\%). While consultations with psychologists and psychotherapists were frequent, the number of treatment sessions with the same provider did not present sufficient treatment intensity to meet our treatment adequacy indicator. Pharmacological treatments were characterized by adequate medication and dosage in half of patients, but regular follow up was lacking. This could in part be explained by the long-term GAD symptoms for over two third of the sample, where close follow up may not be as compulsory when medication is stabilized. As seen in other studies [57], our data on medication use also suggested that a large proportion of patients were taking benzodiazepines in the long term, despite clear guidance that it should be a short-term adjunct medication [34].

We examined predisposing, enabling and needs factors associated to treatment adequacy for GAD. Detection of GAD by a health professional in the past 12 months was an enabling factor for both types of treatment adequacy, with patients being over three times more likely to receive adequate treatment, and suggests that improving recognition of GAD in primary care could lead to an increase in guideline-concordant care. Having a family physician was also an enabling factor for pharmacotherapy adequacy, which is most likely related to continuity of care and patient follow up. The presence of comorbid depression was also associated with overall treatment adequacy. Strong patterns of comorbidity between GAD and major depression have been observed in our study, as well as in clinical and community samples [14, 32], and major depression has been associated with treatment adequacy for anxiety 
disorders in a number of studies [41, 42]. However, the presence of a comorbid anxiety disorder reduced the odds of reception of an adequate psychological treatment.

A number of limitations should be considered in the interpretation of the findings. First, the current dataset is based on self-reported data from a cross-sectional primary care mental health survey and differences in the reporting of mental health service use in surveys compared to administrative data has been highlighted in previous studies $[58,59]$. Second, our results offer a partial view of the correlates of treatment adequacy from service utilization data that could be complemented by research on perceived needs for care and provider and clinic characteristics [60]. Further analyses of Dialogue project data revealed that approximately $40 \%$ of the participants perceived unmet needs for mental health care, in particular for psychotherapy [61]. Third, our indicators of treatment adequacy should not be interpreted as a straightforward criterion for evidence-based treatments, as patient preference, clinical expertise, help seeking behaviour and other patient, provider and system factors are associated with quality of care. We tried to get a sense of the provision of a full course of evidence-based psychotherapy by examining the number of sessions of psychotherapy or counselling with the same provider in the past 12 months comprising CBT components. A total of 12 sessions may arguably be too severe as low intensity interventions for anxiety disorders are gradually gaining empirical support [62]. Furthermore, we relied on self-reported type of psychotherapy and we did not assess specific cognitive behaviour therapy components, which according to research conducted by Stein et al. (2004, 2011), could have led to lower treatment adequacy rates $[39,40]$.

\section{Conclusion}

Our study offers an original perspective on treatment adequacy for GAD with a large primary care sample, where participants are in contact with health care services and the assessment of mental disorders is independent of primary care provider diagnosis and treatment. Our findings suggest that GAD is often recognized in the context of real world primary care, and that over a third of patients are treated according to clinical guidelines recommendations. Detection of GAD is an important correlate of treatment adequacy, and this suggests that further efforts should be invested in specific GAD screening and diagnosis. Also, while it is advocated that GAD patients should be treated in primary care to reduce stigma and improve access to care, some of the main challenges to improving care will be to ensure that patients with a GAD medication obtain a regular follow up and also that patients have sufficient access to evidence-based psychotherapy. Having a family physician was associated with pharmacotherapy adequacy, and primary care providers could also be very influential in referring patients to psychotherapy, providing a lessening of the barriers in access to psychologists. The vast majority of patients with GAD seek care from general practitioners, and this is an optimal context for shared decision-making when a multiplicity of treatment choices and resources are available in the community for patients with anxiety disorders. These efforts could lead to improved detection and evidence-based treatment rates for GAD patients in the primary care setting.

\section{Competing interests}

The authors declare that they have no competing interests.

\section{Authors' contributions}

$L F, P R, A D$ conceived the study and participated in its design and coordination. PR, FNL, IR, ML, MMTB contributed to the analysis and interpretation of the data, and drafted the manuscript. All authors read and approved the final manuscript.

\section{Acknowledgements}

The Dialogue project was funded by the Canadian Health Services Research Foundation, the Fonds de recherche du Québec-Santé (FRQS), the Institut national de santé publique du Québec, the Quebec Ministry of Health and Social Services, and the Groupe interdisciplinaire de recherche sur les urgences. PR was supported by a research scholarship from the FRQS and LF by an applied public health chair from the Canadian Institutes of Health Research (CIHR), FRQS and MSSS. AD was supported by doctoral award from the FRQS.

The authors extend thanks to all the patients as well as clinicians and administrators at each of the study sites participating in the study.

\section{Author details}

${ }^{1}$ Department of Family Medicine and Emergency Medicine, Faculty of Medicine and Health Sciences, Université de Sherbrooke, 3001,12th Avenue North, Sherbrooke, QC J1H 5 N4, Canada. ${ }^{2}$ Division of Neurology, Faculty of Medicine and Health Sciences, Université de Sherbrooke, 3001,12th Avenue North, Sherbrooke, QC J1H 5 N4, Canada. ${ }^{3}$ Faculty of Nursing, Université de Montréal, Pavillon Marguerite-d'Youville, C.P. 6128 succ. Centre-ville, Montreal, QC H3C 3 J7, Canada. ${ }^{4}$ CRCHUM (Centre de recherche du Centre Hospitalier de I'Université de Montréal), Université de Montréal, Pavillon Édouard-Asselin, 264, boul. René-Lévesque Est, Montréal, QC H2X 1P1, Canada.

Received: 12 August 2015 Accepted: 6 October 2015

Published online: 22 October 2015

\section{References}

1. American Psychiatric Association. Diagnostic and statistical manual of mental disorders. 5th ed. Arlington, VA: American Psychiatric Publishing; 2013.

2. Tyrer $P$, Baldwin D. Generalised anxiety disorder. Lancet. 2006;368(9553):2156-66.

3. Wittchen HU, Beesdo K, Bittner A, Goodwin RD. Depressive episodesevidence for a causal role of primary anxiety disorders? Eur Psychiatry. 2003;18(8):384-93.

4. Yonkers KA, Dyck IR, Warshaw M, Keller MB. Factors predicting the clinical course of generalised anxiety disorder. Br J Psychiatry. 2000;176:544-9.

5. Ballenger JC, Davidson JR, Lecrubier Y, Nutt DJ, Borkovec TD, Rickels K, et al. Consensus statement on generalized anxiety disorder from the International Consensus Group on Depression and Anxiety. J Clin Psychiatry. 2001;62 Suppl 11:53-8.

6. Bruce SE, Yonkers KA, Otto MW, Eisen JL, Weisberg RB, Pagano M, et al. Influence of psychiatric comorbidity on recovery and recurrence in generalized anxiety disorder, social phobia, and panic disorder: a 12-year prospective study. Am J Psychiatry. 2005;162(6):1179-87.

7. Kessler RC, Berglund P, Demler O, Jin R, Merikangas KR, Walters EE. Lifetime prevalence and age-of-onset distributions of DSM-IV disorders in the National Comorbidity Survey Replication. Arch Gen Psychiatry. 2005;62(6):593-602. 
8. Wittchen HU, Kessler RC, Beesdo K, Krause P, Hofler M, Hoyer J. Generalized anxiety and depression in primary care: prevalence, recognition, and management. J Clin Psychiatry. 2002;63 Suppl 8:24-34.

9. Munk-Jorgensen P, Allgulander C, Dahl AA, Foldager L, Holm M, Rasmussen l, et al. Prevalence of generalized anxiety disorder in general practice in Denmark, Finland, Norway, and Sweden. Psychiatr Serv. 2006;57(12):1738-44

10. Kroenke K, Spitzer RL, Williams JB, Monahan PO, Lowe B. Anxiety disorders in primary care: prevalence, impairment, comorbidity, and detection. Ann Intern Med. 2007;146(5):317-25.

11. Kessler RC, DuPont RL, Berglund P, Wittchen HU. Impairment in pure and comorbid generalized anxiety disorder and major depression at 12 months in two national surveys. Am J Psychiatry. 1999;156(12):1915-23.

12. Wittchen HU, Carter RM, Pfister H, Montgomery SA, Kessler RC. Disabilities and quality of life in pure and comorbid generalized anxiety disorder and major depression in a national survey. Int Clin Psychopharmacol. 2000;15(6):319-28.

13. Kessler RC, Berglund PA, Dewit DJ, Ustun TB, Wang PS, Wittchen HU Distinguishing generalized anxiety disorder from major depression: prevalence and impairment from current pure and comorbid disorders in the US and Ontario. Int J Methods Psychiatr Res. 2002;11(3):99-111.

14. Hunt C, Slade T, Andrews G. Generalized anxiety disorder and major depressive disorder comorbidity in the National Survey of Mental Health and Well-Being. Depress Anxiety. 2004;20(1):23-31.

15. Revicki DA, Travers K, Wyrwich KW, Svedsater H, Locklear J, Mattera MS, et al. Humanistic and economic burden of generalized anxiety disorder in North America and Europe. J Affect Disord. 2012;140(2):103-12.

16. Hoffman DL, Dukes EM, Wittchen HU. Human and economic burden of generalized anxiety disorder. Depress Anxiety. 2008;25(1):72-90.

17. Andrews G, Sanderson K, Slade T, Issakidis C. Why does the burden of disease persist? Relating the burden of anxiety and depression to effectiveness of treatment. Bull World Health Organ. 2000;78(4):446-54.

18. Olfson M, Gameroff MJ. Generalized anxiety disorder, somatic pain and health care costs. Gen Hosp Psychiatry. 2007;29(4):310-6.

19. Stein DJ. Comorbidity in generalized anxiety disorder: impact and implications. J Clin Psychiatry. 2001;62 Suppl 11:29-36.

20. Schoevers RA, Deeg DJ, Van Tilburg W, Beekman AT. Depression and generalized anxiety disorder: co-occurrence and longitudinal patterns in elderly patients. Am J Geriatr Psychiatry. 2005;13(1):31-9.

21. Wittchen HU, Zhao S, Kessler RC, Eaton WW. DSM-III-R generalized anxiety disorder in the National Comorbidity Survey. Arch Gen Psychiatry. 1994;51(5):355-64.

22. Roy-Byrne PP, Davidson KW, Kessler RC, Asmundson GJ, Goodwin RD, Kubzansky L, et al. Anxiety disorders and comorbid medical illness. Gen Hosp Psychiatry. 2008;30(3):208-25.

23. Ustun TB, Sartorius N. Eds: Mental Illness in General Health Care: an International Study. Chichester (England): John Wiley; 1995.

24. Harman JS, Rollman BL, Hanusa BH, Lenze EJ, Shear MK. Physician office visits of adults for anxiety disorders in the United States, 1985-1998. J Gen Intern Med. 2002;17(3):165-72.

25. Rickels K, Rynn MA. What is generalized anxiety disorder? J Clin Psychiatry. 2001:62 Suppl 11:4-12. discussion 13-14.

26. Calleo J, Stanley MA, Greisinger A, Wehmanen O, Johnson M, Novy D, et al. Generalized anxiety disorder in older medical patients: diagnostic recognition, mental health management and service utilization. J Clin Psychol Med Settings. 2009;16(2):178-85.

27. Olsson I, Mykletun A, Dahl AA. Recognition and treatment recommendations for generalized anxiety disorder and major depressive episode: a cross-sectional study among general practitioners in Norway. Prim Care Companion J Clin Psychiatry. 2006;8(6):340-7.

28. Janssen EH, van de Ven PM, Terluin B, Verhaak PF, Van Marwijk HW, Smolders $M$, et al. Recognition of anxiety disorders by family physicians after rigorous medical record case extraction: results of the Netherlands Study of Depression and Anxiety. Gen Hosp Psychiatry. 2012;34(5):460-7.

29. Hoehn-Saric R. Generalized anxiety disorder in medical practice. Prim Psychiatry. 2005;12:30-4.

30. Barbee JG, Todorov AA, Kuczmierczyk AR, Mancuso DM, Schwab JJ, Maddock RJ, et al. Explained and unexplained medical symptoms in generalized anxiety and panic disorder: relationship to the somatoform disorders. Ann Clin Psychiatry. 1997;9(3):149-55.

31. Klap R, Unroe KT, Unutzer J. Caring for mental illness in the United States: a focus on older adults. Am J Geriatr Psychiatry. 2003;11(5):517-24.
32. Judd LL, Kessler RC, Paulus MP, Zeller PV, Wittchen HU, Kunovac JL. Comorbidity as a fundamental feature of generalized anxiety disorders: results from the National Comorbidity Study (NCS). Acta Psychiatr Scand Suppl. 1998;393:6-11.

33. Antony MM, Stein MB. Oxford handbook of anxiety and related disorders. New York: Oxford University Press; 2009.

34. Swinson RP, Antony M, Bleau P, Chokka P, Craven M, Fallu A, et al.. Clinical practice guidelines: Management of anxiety disorders. Can J Psychiatr. 2006;51 Suppl 2:1-92.

35. National Institute for Health and Care Excellence Generalized anxiety disorder and panic disorder (with or without agoraphobia) in adults. In: Management in primary care, secondary care and community care. London, UK: National Institute for Health and Clinical Excellence; 2011.

36. Fernandez A, Haro JM, Codony M, Vilagut G, Martinez-Alonso M, Autonell J, et al. Treatment adequacy of anxiety and depressive disorders: primary versus specialised care in Spain. J Affect Disord. 2006;96(1-2):9-20.

37. Wang PS, Berglund P, Kessler RC. Recent care of common mental disorders in the United States : prevalence and conformance with evidence-based recommendations. J Gen Intern Med. 2000;15(5):284-92.

38. Wang PS, Lane M, Olfson M, Pincus HA, Wells KB, Kessler RC. Twelve-month use of mental health services in the United States: results from the National Comorbidity Survey Replication. Arch Gen Psychiatry. 2005;62(6):629-40.

39. Stein MB, Roy-Byrne PP, Craske MG, Campbell-Sills L, Lang AJ, Golinelli D, et al. Quality of and patient satisfaction with primary health care for anxiety disorders. J Clin Psychiatry. 2011;72(7):970-6.

40. Stein MB, Sherbourne CD, Craske MG, Means-Christensen A, Bystritsky A, Katon W, et al. Quality of care for primary care patients with anxiety disorders. Am J Psychiatry. 2004;161(12):2230-7.

41. Prins MA, Verhaak PF, Smolders M, Laurant MG, van der Meer K, Spreeuwenberg $P$, et al. Patient factors associated with guideline-concordant treatment of anxiety and depression in primary care. J Gen Intern Med. 2010;25(7):648-55.

42. Roberge $P$, Fournier L, Duhoux A, Nguyen $C T$, Smolders M. Mental health service use and treatment adequacy for anxiety disorders in Canada. Soc Psychiatry Psychiatr Epidemiol. 2011;46(4):321-30.

43. Wang PS, Aguilar-Gaxiola S, Alonso J, Angermeyer MC, Borges G, Bromet EJ, et al. Use of mental health services for anxiety, mood, and substance disorders in 17 countries in the WHO world mental health surveys. Lancet. 2007:370(9590):841-50

44. Andersen RM. Revisiting the behavioral model and access to medical care: does it matter? J Health Soc Behav. 1995;36(1):1-10.

45. Katzman MA, Bleau P, Blier P, Chokka P, Kjernisted K, Van Ameringen M, et al. Canadian clinical practice guidelines for the management of anxiety, posttraumatic stress and obsessive-compulsive disorders. BMC Psychiatry. 2014;14 Suppl 1:S1-S83.

46. Duhoux A, Fournier L, Gauvin L, Roberge P. Quality of care for major depression and its determinants: a multilevel analysis. BMC Psychiatry. 2012;12(1):142

47. Zigmond AS, Snaith RP. The Hospital Anxiety and Depression Scale. Acta Psychiatr Scand. 1983;67(6):361-70.

48. Roberge $\mathrm{P}$, Dore I, Menear M, Chartrand E, Ciampi A, Duhoux A, et al. A psychometric evaluation of the French Canadian version of the Hospital Anxiety and Depression Scale in a large primary care population. J Affect Disord. 2013;147(1-3):171-9.

49. Kovess V, Fournier L, Lesage AD, Lebigre FA, Caria A. Two validation studies of the CIDIS: a simplified version of the composite international diagnostic interview. Psychiatric Networks. 2001;4(1-2):10-24.

50. Fernandez A, Haro JM, Martinez-Alonso M, Demyttenaere K, Brugha TS, Autonell J, et al. Treatment adequacy for anxiety and depressive disorders in six European countries. Br J Psychiatry. 2007;190:172-3.

51. Smolders $M$, Laurant $M$, Verhaak $P$, Prins $M$, Van Marwijk H, Penninx B, et al. Adherence to evidence-based guidelines for depression and anxiety disorders is associated with recording of the diagnosis. Gen Hosp Psychiatry. 2009;31(5):460-9.

52. Prins MA, Verhaak PF, Hilbink-Smolders M, Spreeuwenberg P, Laurant MG, van der Meer K, et al. Outcomes for depression and anxiety in primary care and details of treatment: a naturalistic longitudinal study. BMC Psychiatry. 2011;11:180.

53. Diez-Roux AV. Multilevel analysis in public health research. Annu Rev Public Health. 2000;21:171-92.

54. Thompson A, Hunt C, Issakidis C. Why wait? Reasons for delay and prompts to seek help for mental health problems in an Australian clinical sample. Soc Psychiatry Psychiatr Epidemiol. 2004;39(10):810-7. 
55. Culpepper L. Generalized anxiety disorder in primary care: emerging issues in management and treatment. J Clin Psychiatry. 2002;63 Suppl 8:35-42.

56. Allgulander C. Generalized anxiety disorder: What are we missing? Eur Neuropsychopharmacol. 2006:16 Suppl 2:S101-8.

57. Smolders M, Laurant M, Van Rijswijk E, Mulder J, Braspenning J, Verhaak $P$, et al. The impact of co-morbidity on GPs' pharmacological treatment decisions for patients with an anxiety disorder. Fam Pract. 2007:24(6):538-46.

58. Drapeau A, Boyer R, Diallo FB. Discrepancies between survey and administrative data on the use of mental health services in the general population: findings from a study conducted in Quebec. BMC Public Health. 2011;11:837.

59. Palin JL, Goldner EM, Koehoorn M, Hertzman C. Prevalence and frequency of mental health care provided by general practitioners: differences between 2 national data sources for the same population. Can J Psychiatry. 2012;57(6):366-74.

60. Levesque J-F, Harris MF, Russell G. Patient-centred access to health care: conceptualising access at the interface of health systems and populations. Int J Equity Health. 2013;12:18.

61. Dezetter A, Duhoux A, Menear M, Roberge P, Chartrand E, Fournier L. Reasons and determinants for perceiving unmet needs for mental health in primary care in Quebec. Can J Psychiatry. 2015;60(6):284-93.

62. Bennett-Levy J, Richards DA, Farrand P, Christensen H, Griffiths KM, Kavanagh DJ, et al. Oxford guide to low intensity CBT interventions. New York: Oxford University Press; 2010.

\section{Submit your next manuscript to BioMed Central and take full advantage of:}

- Convenient online submission

- Thorough peer review

- No space constraints or color figure charges

- Immediate publication on acceptance

- Inclusion in PubMed, CAS, Scopus and Google Scholar

- Research which is freely available for redistribution 